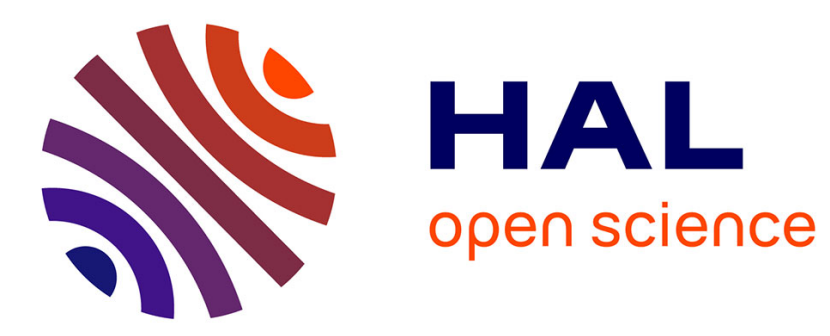

\title{
Heterozygosity and parasite intensity: lung parasites in the water frog hybridization complex
}

Pierre Joly, Vanessa Guesdon, Emmanuelle Gilot-Fromont, Sandrine Plénet, Odile Grolet, J.F. Guégan, S. Hurtrez-Boussès, F. Thomas, F. Renaud

\section{- To cite this version:}

Pierre Joly, Vanessa Guesdon, Emmanuelle Gilot-Fromont, Sandrine Plénet, Odile Grolet, et al.. Heterozygosity and parasite intensity: lung parasites in the water frog hybridization complex. Parasitology, 2007, 135 (1), pp.95-104. 10.1017/S0031182007003599 . halsde-00222991

\section{HAL Id: halsde-00222991 https://hal.science/halsde-00222991}

Submitted on 17 May 2021

HAL is a multi-disciplinary open access archive for the deposit and dissemination of scientific research documents, whether they are published or not. The documents may come from teaching and research institutions in France or abroad, or from public or private research centers.
L'archive ouverte pluridisciplinaire HAL, est destinée au dépôt et à la diffusion de documents scientifiques de niveau recherche, publiés ou non, émanant des établissements d'enseignement et de recherche français ou étrangers, des laboratoires publics ou privés.

\section{(c)(1)}

Distributed under a Creative Commons Attribution| 4.0 International License 


\title{
Heterozygosity and parasite intensity: lung parasites in the water frog hybridization complex
}

\author{
P. JOLY ${ }^{1 *}$, V. GUESDON ${ }^{1}$, E. FROMONT ${ }^{2}$, S. PLENET ${ }^{1}$, O. GROLET ${ }^{1}$, J. F. GUEGAN ${ }^{3}$, \\ S. HURTREZ-BOUSSES ${ }^{3}$, F. THOMAS ${ }^{3}$ and F. RENAUD ${ }^{3}$ \\ ${ }^{1}$ UMR 5023 Ecology of Fluvial Hydrosystems, Université Claude Bernard Lyon1, F-69622 Villeurbanne, France \\ ${ }^{2}$ UMR 5558 Biometry and Evolutionary Biology, Université Claude Bernard Lyon1, F-69622 Villeurbanne, France \\ ${ }^{3}$ UMR CNRS-IRD 9926, Centre for the Study of Micro-organism Polymorphism, 911 Avenue Agropolis - BP 5045, \\ F-34032 Montpellier Cedex 1, France
}

\begin{abstract}
SUMMAR Y
In hybridogenetic systems, hybrid individuals are fully heterozygous because one of the parental genomes is discarded from the germinal line before meiosis. Such systems offer the opportunity to investigate the influence of heterozygosity on susceptibility to parasites. We studied the intensity of lung parasites (the roundworm Rhabdias bufomis and the fluke Haplometra cylindracea) in 3 populations of water frogs of the Rana lessonae-esculenta complex in eastern France. In these mixed populations, hybrid frogs (R.esculenta) outnumbered parental ones (R. lessonae). Despite variation in parasite intensity and demographic variability among populations, the relationship between host age and intensity of parasitism suggests a higher susceptibility in parentals than in hybrids. Mortality is probably enhanced by lung parasites in parental frogs. On the other hand, while parental frogs harboured higher numbers of $H$. cylindracea than hybrid frogs, the latter had higher numbers of $R$. bufonis. Despite such discrepancies, these results support the hybrid resistance hypothesis, although other factors, such as differences in body size, age-related immunity, differential exposure risks and hemiclonal selection, could also contribute to the observed patterns of infection.
\end{abstract}

Key words: hybrid, hybridogenesis, water frogs, Rana species, lung parasites, Rhabdias bufonis, Haplometra cylindracea.

\section{INTRODUCTION}

Because hybridization produces innovative genetic combinations by joining two different genomes, performance analysis of hybrid individuals may contribute to the study of host-parasite coevolution (Moulia et al. 1995; Arnold, 1997). The current concepts about the evolution of hybrid-parasite systems do not, however, allow the proposal of monolithic hypotheses, probably because of the great diversity of genetic associations covered by the term 'hybridization' (from subspecies to genus). While hybridization between phylogenetically distant genomes is expected to promote high susceptibility to the parasite, because of breakdown of genetic coadaptation, hybridization between closely related taxa could enhance resistance through a heterosis effect (Sage et al. 1986; Dupont and Crivelli, 1988; Whitman, 1989; Moulia, 1999). The hypotheses established by Fritz et al. (1999) for predicting the impact of herbivory in plants provide an initial theoretical framework for the study of parasitehybrid systems. Our aim was to focus on the

* Corresponding author: UMR 5023 Ecology of Fluvial Hydrosystems, Université Claude Bernard Lyon1, F69622 Villeurbanne, France. Tel: +33472433 586. Fax: 33472431 141. E-mail: pjoly@biomserv.univ-lyon1.fr divergence between susceptibility and resistance, taking advantage of the hybridogenetic system of the water frogs of the Rana lessonae-esculenta complex. In a hybridogenetic complex, the genome of one parental species carries distorter genes, which induce the elimination of the genome material of the other parental species before meiosis in the germ line of hybrids (Schultz, 1969; Tunner 1974; Joly 2001). The distorter genome is then duplicated and the gametes of hybrid individuals carry only the genome of one of the parental species. These hybrids usually breed with the taxon whose genome is eliminated, thus restoring the hybridness of their descent (sexual parasitism). In the hybrid lineages, the distorter genome is transmitted clonally (hemiclones). Because of the lack of recombination between the parental genomes ( $c f$ Pagano and Schmeller, 1999), hybrids are genetically similar to F1 hybrids. In one of the water frog complexes ( $R$. lessonae [ $L L$ genome] and its hybridogen $R$. esculenta $[R L$ genome], which carries a ridibunda [ $R$ hemigenome]), the success of hybrid lineages has been widely analysed; several studies (Tunner and Nopp, 1979; Berger and Uzzell, 1980; Semlitsch, 1993, Hotz et al. 1999) support the hypothesis of heterotic advantage with respect to fecundity, predation avoidance or hypoxic tolerance of froglets (heterosis effect). However, other studies (Pagano et al. 2001; Plénet et al. $2000 a, b$, 
2005 ; Negovetic et al. 2001) support a simple additive hypothesis with regard to habitat use, hypoxic tolerance of tadpoles and thermal tolerance (intermediate performances of the hybrids). The water frog hybridization complex thus makes it possible to investigate in situ the relationship between hybridization and parasite infection by comparing the infection rates of 2 taxa (the hybrid Rana esculenta and the sexual host $R$. lessonae) that occur concomitantly in the same habitats (Rana ridibunda usually does not occur in the same habitats as $R$. lessonae). Water frogs host a great diversity of parasites (Walton, 1949; Saglam and Arikan, 2006) of which we studied the infection with lung parasites Rhabdias bufonis (Nematoda) and Haplometra cylindracea (Trematoda). In the present study, our aim was to compare the intensity of parasite infection between the two taxa of 3 populations occupying fishponds in eastern France. We took advantage of the possibility of determining individual ages by means of skeletochronology, in order to analyse the relationships between age, mortality and parasite accumulation.

MATERIALS AND METHODS

\section{Study sites}

The frogs were sampled on the Dombes Plateau (north-east of Lyon, France), where 1000 fishponds devoted to growing carp are distributed over a $900 \mathrm{~km}^{2}$ area. Water frogs of the LE hybridogenetic complex occur in high densities at the banks of these ponds. We sampled the frogs at 3 ponds: Boufflers pond (designated as POND A) which is within the estate of the Pierre Vérots Foundation, SaintJean-de-Thurigneux $\left(4^{\circ} 51^{\prime} \mathrm{E}-45^{\circ} 56^{\prime} \mathrm{N}\right)$, La Tille pond (POND B) at Saint-André-le-Bouchoux $\left(5^{\circ} 55^{\prime} \mathrm{E}-46^{\circ} 59^{\prime} \mathrm{N}\right)$ and a third pond (POND C) of the Regional Research Institute for Aquaculture (IRRA) at Saint-Nizier-le-Désert $\left(5^{\circ} 10^{\prime} \mathrm{E}-46^{\circ} 04^{\prime} \mathrm{N}\right)$. Because the dispersal range of the water frogs is usually less than $2 \mathrm{~km}$ (Holenweg-Peter, 2001), the present populations can be considered independent, as they are separated from one another by more than $15 \mathrm{~km}$ (i.e. $15 \mathrm{~km}$ between POND B and POND C and $30 \mathrm{~km}$ between POND A and both POND B and POND C).

\section{Sampling, taxon identification, age estimation and measurements}

We decided to focus on females because of their crucial importance in population dynamics. We sampled frogs from the end of April to the end of May during the breeding period. They were caught by hand during the night using spotlights. We sampled the whole perimeter of each pond. Juvenile frogs $(<40 \mathrm{~mm})$ and males were directly released, whereas females were frozen until performing tissue sampling and measurements. Length from snout to urostyle was measured to the closest $0.1 \mathrm{~mm}$ using callipers. We measured body mass after removing the ovaries, which were weighed separately. We estimated body condition by the residuals of the regression of body mass on body length, both measurements being converted into natural logarithms. This index was used because it was shown to be independent of the population under consideration (Jakob et al. 1996). Body condition was defined independently for each genotype, because the relationship between body mass and length was considered to vary according to the genotype considered. We identified parental species from hybrids by specific allozymic markers detected by protein electrophoresis of finger tissue using lactate dehydrogenase (LDH-B; EC 1.1.1.27) and mannose-6phosphate isomerase (MPI; EC 5.3.1.8) (Beerli, 1994; Pagano et al. 1997). We estimated individual age by skeletochronology performed on finger bones (Castanet et al. 1977; Augert and Joly, 1993).

\section{Lung parasites}

We elected to specifically study lung parasites after performing a preliminary analysis of the parasite intensity of the whole body (40 frogs examined). The parasite fauna was mainly composed of roundworms and flukes in the digestive tract and in the lungs. Because lung parasites (Rhabdias bufonis and Haplometra cylindracea) were frequent and their damage to lung tissues was expected to be more severe than that of gastrointestinal parasites, we focussed on them. While we identified the roundworm as Rhabdias bufonis, the recent discovery of new species identified in North and Central America (Tkach et al. 2006; Kuzmin et al. 2007) suggests that the taxonomy of the genus Rhabdias needs to be revised. However, we decided to use this taxon name until further systematic and phylogenetic investigations have been performed in Europe. We extracted the parasites from the lungs by dissection under a stereoscopic microscope. They were then fixed on microscope glass slides using lactophenol for further examinations. We calculated parasite occurrence (presence of parasite), parasite intensity (total number of parasites; Bush et al. 1997), and parasite diversity $(0,1$ or 2 species $)$.

\section{Data analysis}

In order to describe population structure and detect variability between populations, we first compared the structures of the three populations (hybrid proportions, age, body condition and parasite intensity). Hybrid proportions were compared using $\chi^{2}$. Age structures were analysed by using a proportional-odds model, which is a generalized linear 
model that relates an ordinal response variable (here age) to predictor variables (MacCullagh and Nelder, 1989; Guisan and Harrell, 2000). The procedure of model selection is described in the following. We first adjusted all possible models, including 1 or 2 of the tested predictor variables, and their interactions. Tests of the effects of variables or interactions were done by use of the likelihood ratio test (LRT) based on the difference in deviance between 2 nested models, which follows a chi-square distribution (Agresti 1990). All variables or interactions that tended to influence the variable considered $(P<0 \cdot 2$ using the LRT) were combined into a single model, from which redundant terms were finally removed. The goodness-of-fit of the selected model was assessed through analysis of deviance residuals as well as comparison of the residual deviance with a chi-square distribution. Finally, we interpreted the selected model using the parameter estimates and their confidence intervals (Agresti, 1990). To compare body condition among populations, we used linear models and ANOVA after assessing the normality of body condition by visual inspection of observed versus theoretical quantiles (Venables and Ripley, 2002). We analysed parasite intensity because it was expected to be more informative than simple presence-absence. For this purpose, we used a negative binomial model, which is considered appropriate for parasite distributions (Wilson et al. 1996). Here, the negative binomial distribution was also probable, due to the high variance-to-mean ratio. Negative binomial models relate the number of parasites found in a given individual to the predictor variables, considering that the number of parasites follows a negative binomial distribution (Lawless, 1987). We first tested whether the observed distribution fitted a negative binomial distribution by adjusting the null (i.e. constant) negative binomial model to obtain a maximum-likelihood estimate of the dispersion parameter $\hat{\theta}_{1}$ and then by comparing the observed distribution with the expected distribution using visual inspection of the observed versus theoretical quantiles. We also estimated the dispersion parameter using the classical estimate from the mean $\bar{x}$ and vairance $s^{2}$ of the data set:

$$
\hat{\theta}_{2}=\frac{\bar{x}^{2}}{s^{2}-\bar{x}}
$$

to ensure that no discrepancy occurred between $\hat{\theta}_{1}$ and $\hat{\theta}_{2}$ (Wilson et al. 1996). Then we adjusted all negative binomial models combining the tested predictor variables and their interactions, always assuming that the dispersion parameter equalled $\hat{\theta}_{1}$ to obtain comparable models. Model selection and analysis were performed using the procedure described above for proportional-odds models.

Because population structures differed (see Results section), the dynamics of parasite infection was expected to vary among sites, thus parasite intensity was analysed separately in each population. We tested the effects of 4 predictor variables and their interactions since the aim of the study was to investigate the influence of genotype (hybrid or parental) on parasite intensity. For each parasite species, we also considered the effects of age, body condition and intensity of the other parasite. Age was studied in order to search for density-dependent patterns, a peaked age-parasite intensity relationship being supposed to reveal parasite-induced host mortality, parasite mortality or age-dependent immunity (Anderson and Gordon, 1982; Hudson et al. 2002). With this aim, age was considered both as a linear trend and as a second-order polynomial, the second-order term being searched for in order to detect a peak in the age-versus-intensity relationship. Finally, the relationship between parasite intensity and host body condition was tested to assess parasite infection capacity (Jakob et al. 1996). If a parasite is pathogenic, individuals harbouring numerous parasites are expected to exhibit poor body condition, unless the parasite is so pathogenic that infected hosts die and are thus not observed. We first searched for possible relationships between the variables used as predictors of parasite intensity. This preliminary analysis was designed to search for co-linearity between predictor variables. We did not test the relationship between body condition and genotype because body condition was defined independently for each genotype. We tested the relationship between genotype and age using a proportional-odds model. The relationship between age and body condition was tested using a linear regression model and ANOVA. These tests were performed separately in each population. To analyse which factors might be associated with parasite intensity, we first estimated the dispersion parameter for each population and verified that the observed distribution was in accordance with a negative binomial distribution. Then model selection and analysis were performed as described for proportional-odds models. All statistical analyses were done with the $\mathrm{R}$ software (Venables and Ripley, 2002), considering an error risk of $0 \cdot 05$.

RESULTS

\section{Population parameters}

Table 1 summarizes population structures and describes parasite distribution in each of the three populations. Since age was not available for all the individuals, the sample size was reduced when studying age. The proportion of hybrids appeared to be higher at POND $\mathrm{C}$ than at the other sites. Whereas the difference was not significant when considering the three sites separately $\left(\chi^{2}=4 \cdot 22\right.$, D.F. $=2, P=0 \cdot 1211)$, it became significant when 
Table 1. Population structure and description of parasite distribution in the three populations

(The relationships between age and genotype and between age and body condition were tested by generalized linear models. For each parasite, 2 estimates of the dispersion parameter are given: $\hat{\theta}_{1}$ is the first estimate (see text for definition) and $\hat{\theta}_{2}$ is the maximum-likelihood estimate obtained by fitting a null negative binomial model. Only 2 individuals from POND C were infected by $R$. bufonis, thus this parasite was not further studied in this population.)

\begin{tabular}{|c|c|c|c|}
\hline & POND A & POND B & POND C \\
\hline Sample size & 112 & 91 & 53 \\
\hline With age available & 96 & 62 & 45 \\
\hline \multicolumn{4}{|l|}{ Age structure } \\
\hline \multicolumn{4}{|l|}{$\begin{array}{l}Y=\text { Numbers } \\
X=\text { Years }\end{array}$} \\
\hline & $\begin{array}{lllllll}2 & 3 & 4 & 5 & 6 & 7 & 8\end{array}$ & $\begin{array}{lllllll}2 & 3 & 4 & 5 & 6 & 7 & 8\end{array}$ & $\begin{array}{lllllll} & & & & & & \\
2 & 3 & 4 & 5 & 6 & 7 & 8\end{array}$ \\
\hline Hybrids (\%) & $74 \cdot 1$ & $72 \cdot 5$ & $86 \cdot 8$ \\
\hline $\begin{array}{l}\text { Age-genotype } \\
\text { relationship }\end{array}$ & $P=0 \cdot 4919$ & $P=0 \cdot 3666$ & $P=0 \cdot 1299$ \\
\hline $\begin{array}{l}\text { Age-body condition } \\
\text { relationship }\end{array}$ & $P=0 \cdot 0525$ & $P=0 \cdot 2507$ & $P=0 \cdot 0227$ \\
\hline \multicolumn{4}{|l|}{ H. cylindracea } \\
\hline prevalence (\%) & $39 \cdot 29$ & $65 \cdot 93$ & $47 \cdot 17$ \\
\hline mean intensity & $4 \cdot 25$ & $3 \cdot 78$ & $4 \cdot 48$ \\
\hline$\hat{\theta}_{1}$ & $0 \cdot 26$ & $0 \cdot 60$ & $0 \cdot 34$ \\
\hline$\hat{\theta}_{2}$ & $0 \cdot 24$ & $0 \cdot 63$ & $0 \cdot 30$ \\
\hline \multicolumn{4}{|l|}{ R. bufonis } \\
\hline prevalence (\%) & $45 \cdot 54$ & $25 \cdot 27$ & $3 \cdot 77$ \\
\hline mean intensity & $2 \cdot 94$ & $3 \cdot 35$ & Not estimated \\
\hline$\theta_{1}$ & $0 \cdot 39$ & $0 \cdot 16$ & Not estimated \\
\hline$\hat{\theta}_{2}$ & $0 \cdot 41$ & $0 \cdot 16$ & Not estimated \\
\hline $\begin{array}{l}\text { Prevalence of double } \\
\text { infection }(\%)\end{array}$ & $21 \cdot 43$ & $16 \cdot 48$ & Not estimated \\
\hline
\end{tabular}

pooling POND B with POND A $\left(\chi^{2}=4 \cdot 15\right.$, D.F. $=1$, $P=0 \cdot 0415)$. Age structure did not significantly differ between taxa, but it differed among populations, all three differences being significant (POND A against POND C, t-value $=2 \cdot 47, P=0.0139 ;$ POND A against $\mathrm{POND} \mathrm{B}: \mathrm{t}-\mathrm{value}=2 \cdot 43, P=0 \cdot 0151 ; \mathrm{POND}$ $\mathrm{B}$ against POND C: t-value $=4 \cdot 62, P<0 \cdot 0001)$. Frogs were, on average, oldest in POND A while they were youngest in POND C (Table 1). Conversely, mean body condition did not differ among populations $(\mathrm{F}$-value $=0 \cdot 6341, P=0 \cdot 5313)$. Whereas the prevalence of $H$. cylindracea was highest in POND B, its intensity did not vary among populations $(\mathrm{LRT}=2 \cdot 55$, D.F. $=2, P=0 \cdot 2880)$. In contrast, the number of $R$. bufonis differed among populations $(\mathrm{LRT}=27 \cdot 28, \quad$ D.F. $=2, \quad P<0 \cdot 0001)$ mainly because this species was rare at POND C. The prevalence of $R$. bufonis was highest in POND A. Taken together, these results show that the three populations had distinct demographic parameters with the lowest apparent mortality at POND A and the highest at POND C where it was related to both a high proportion of hybrids and to the fact that $R$. bufonis was almost absent.

Age structures were not related to genotype ( $L L$ versus $R L$ ) in any of the three populations
(Table 1). At POND C particularly, survival of $R L$ individuals appeared higher than that of $L L$ ones, but the difference was not significant. In this population, age explained a significant part of body condition since body condition decreased with age (Table 1). This relationship supports the hypothesis of high adult mortality in that population. The tendency of decreasing body condition with age was also close to the chosen significance level at Pond A, while it was clearly not significant at POND B (Table 1).

\section{Intensity of $\mathrm{H}$. cylindracea infection}

While the selected model varied from one population to another, the genotype was always involved as a significant variable (Table 2). The residual deviance of the selected models followed a chi-squared distribution for POND B and POND C, but showed data underdispersion for POND A, thus suggesting that individuals were more similar than expected. The deviance residuals failed, however, in detecting any particular structure. The POND A population was the only one in which the intensity of H. cylindracea was related to body condition (LRT $=2 \cdot 521$, D.F. $=1, P=0 \cdot 044)$. H. cylindracea intensity was 
Table 2. Model selection for the intensity of Haplometra cylindracea and Rana bufonis infection in the three populations

\begin{tabular}{|c|c|c|}
\hline & $\begin{array}{l}\text { Variables related } \\
\text { to parasite load } \\
(P \text {-value of LRT })\end{array}$ & $\begin{array}{l}\text { Model selected, } \\
\text { residual deviance } \\
\text { (residual D.F.) }\end{array}$ \\
\hline H. cylindracea in POND B & 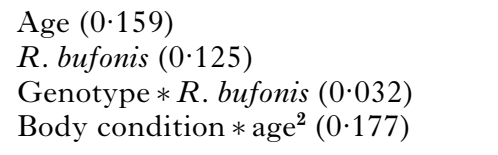 & Genotype $* R$. bufonis \\
\hline H. cylindracea in POND C & $\begin{array}{l}\text { Body condition }(0 \cdot 032) \\
\text { Age }(0 \cdot 086) \\
\text { Genotype } * \text { age }(0 \cdot 044)\end{array}$ & $\begin{array}{l}\text { Genotype } * \text { age } \\
31 \cdot 33(41)\end{array}$ \\
\hline H. cylindracea in POND A & $\begin{array}{l}\text { Body condition }(0 \cdot 007) \\
\text { Genotype }(0 \cdot 013) \\
\text { Age }(0 \cdot 154) \\
\text { Genotype } * \text { age }(0 \cdot 007) \\
\text { Body condition } * \text { age }(0 \cdot 141) \\
\text { Body condition } * \text { R. bufonis }(0 \cdot 192) \\
R . \text { bufonis } * \text { age }^{2}(0 \cdot 134)\end{array}$ & $\begin{array}{l}\text { Genotype } * \text { age }+ \\
\text { body condition }\end{array}$ \\
\hline R. bufonis in POND B & $\begin{array}{l}\text { Genotype }(0 \cdot 096) \\
H . \text { cylindracea }(0 \cdot 171) \\
\text { Genotype } * H . \text { cylindracea }(0 \cdot 010) \\
\text { Genotype } * \operatorname{age}^{2}(0 \cdot 063) \\
\text { Body condition } * \operatorname{age}^{2}(0 \cdot 109) \\
H . \text { cylindracea } * \text { age }(0 \cdot 176)\end{array}$ & Genotype $* H$. cylindracea \\
\hline R. bufonis in POND A & $\begin{array}{l}\text { Genotype }(0 \cdot 187) \\
\text { Body condition } * \text { age }(0 \cdot 052)\end{array}$ & $\begin{array}{l}\text { Null } \\
98 \cdot 65(111)\end{array}$ \\
\hline
\end{tabular}

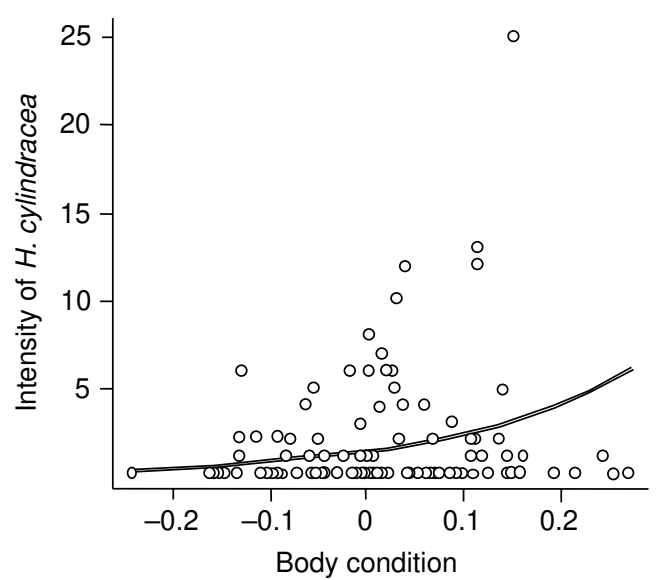

Fig. 1. Relationship between body condition and the intensity of Haplometra cylindracea in pond A. Observed data (circles) and predictions of the model including the effect of body condition alone (line).

indeed the lowest in individuals experiencing the lowest body condition (Fig. 1).

At both POND $\mathrm{C}$ and POND $\mathrm{A}$, the interaction between genotype and age was significant (POND C: $\mathrm{LRT}=3 \cdot 92$, D.F. $=1, P=0 \cdot 044$; POND A : LRT $=$ $4 \cdot 767$, D.F. $=1, P=0 \cdot 006)$. In these two populations, the intensity of $H$. cylindracea increased with age in $R L$ frogs (Fig. 2). In contrast, the pattern exhibited by $L L$ frogs differed between populations. At POND A, the intensity of $H$. cylindracea decreased as the individuals got older. Conversely, the intensity of $H$. cylindracea increased with age in parental frogs at POND C, but no individual older than 3 years was observed there. Fig. 2 shows that the intensity of $H$. cylindracea in 3 -year-old $L L$ individuals was very high. Taking into account the results for POND A, we hypothesize that $L L$ individuals with high parasite intensity die, so that no individual older than 3 years was observed. Finally, in these two populations, the interaction between age and genotype suggests that parental individuals were more susceptible to $H$. cylindracea than hybrids. At POND B, the selected model was (genotype* intensity of $R$. bufonis). The only significant factor was the interaction $(\mathrm{LRT}=4.849$, D.F. $=1, P=$ $0 \cdot 032)$. The number of $H$. cylindracea tended to increase with the number of $R$. bufonis in parental individuals, whereas hybrids with many $R$. bufonis harboured few H. cylindracea (Fig. 3).

\section{Intensity of $\mathrm{R}$. bufonis infection}

Since only 2 individuals were infested at POND C, we analysed the intensity of $R$. bufonis only in the populations of POND A and POND B. The selected model for POND B showed underdispersion, while the best fit was obtained with the null model for POND A (Table 2). At POND B, the selected model was (genotype $* H$. cylindracea intensity), thus converging with the results obtained for $H$. cylindracea. 


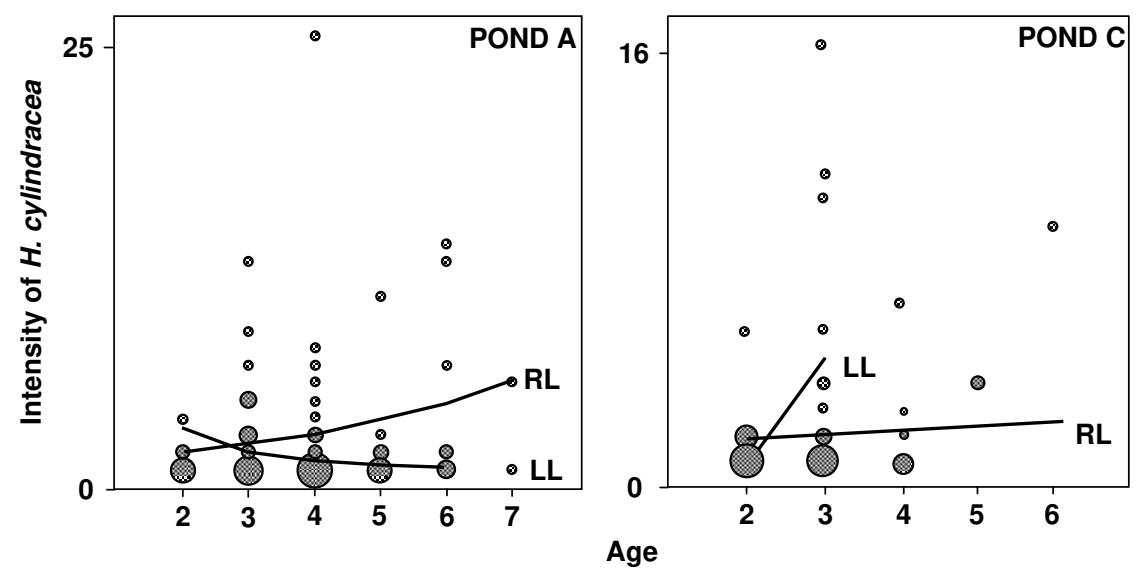

Fig. 2. Relationship between age and intensity of Haplometra cylindracea in POND A and POND C populations. Observed data (circles) and predictions of the selected models (lines). LL: parental Rana lessonae frogs; RL: hybrid R. esculenta frogs. The size of the circles is proportional to the number of individuals observed. Largest circle: $n=18$ at POND A, $n=11$ at POND C.
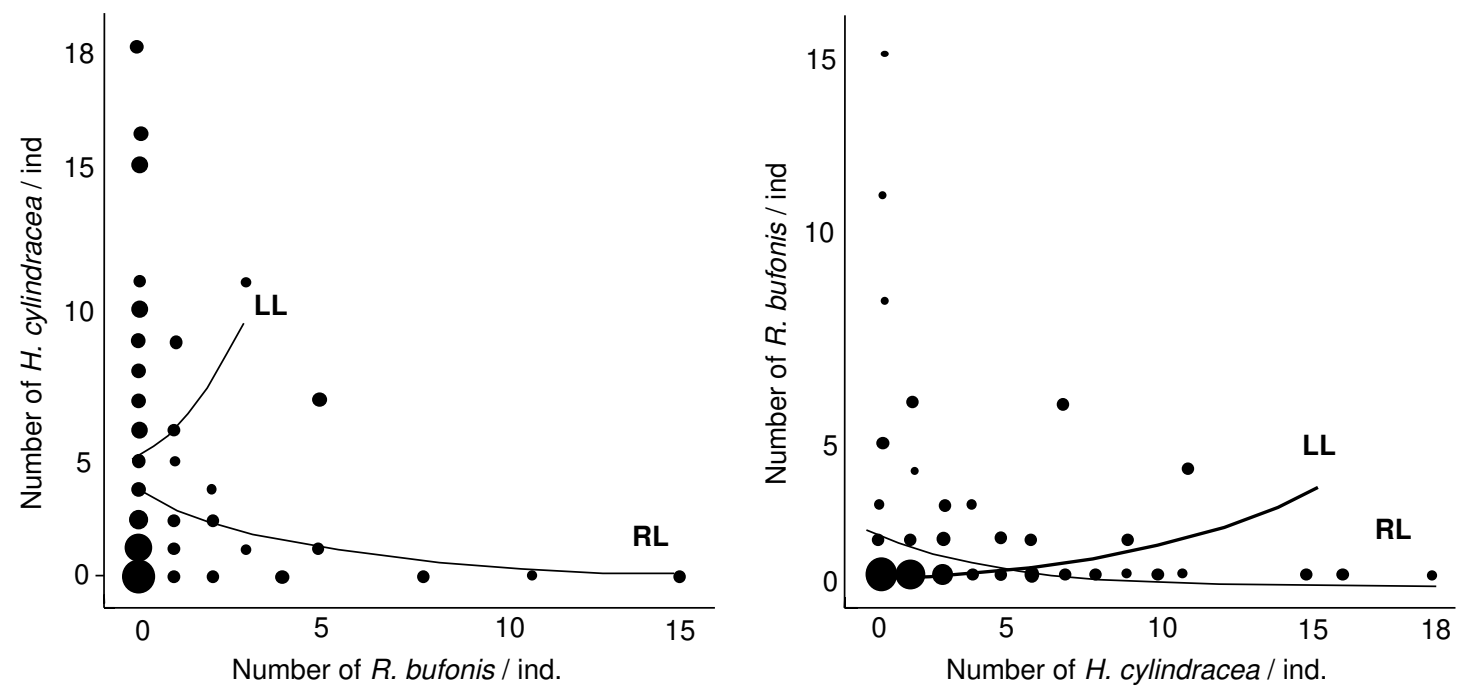

Fig. 3. Relationship between intensity of Haplometra cylindracea and Rana bufonis in the water frogs of the POND B population, and interaction with genotype. Left: H. cylindracea as a function of R. bufonis. Right: R. bufonis as a function of H. cylindracea. Dots are observed data and lines are predictions of the selected models. Dot size is proportional to frog numbers with largest dots $=23$ frogs. $\mathrm{LL}=$ Rana lessonae parental species. $\mathrm{RL}=R$. esculenta hybrid.

In this population, parental individuals carrying numerous $H$. cylindracea also harboured many R. bufonis. Conversely, hybrids with many H. cylindracea had few $R$. bufonis, and individuals with many R. bufonis had few H. cylindracea (Fig. 3).

\section{Variation between populations}

Because the pattern in POND B population differed from those in the other populations, we performed complementary analyses to understand which environment or population factors could explain this difference. First, we tested whether parasite incidence differed among populations by comparing the number of $H$. cylindracea in 2-year-old frogs among populations, using a proportional-odds model. The difference was significant $(\mathrm{LRT}=8 \cdot 35$, D.F. $=2$, $P=0 \cdot 0154)$. Whereas young frogs carried an average of 4.36 parasites at POND B, the numbers were 0.59 at POND $\mathrm{C}$ and 0.38 at POND A. This result lead us to assume that parasite-induced mortality may occur in hybrids as well as in parental frogs in this population, but that the age at peak prevalence may be $<2$ years. To obtain further indications, we compared the changes in parasite intensity and variance-to-mean ratio (VMR) with age in the three populations (Fig. 4, VMR was calculated only in samples where $n \geqslant 5)$. The pattern in parental frogs was inconsistent, probably due to low sample sizes. In $R L$ frogs, the number of $H$. cylindracea increased with age at POND $\mathrm{A}$ and POND $\mathrm{C}$ but decreased at POND $\mathrm{B}$, suggesting that parasite-induced 

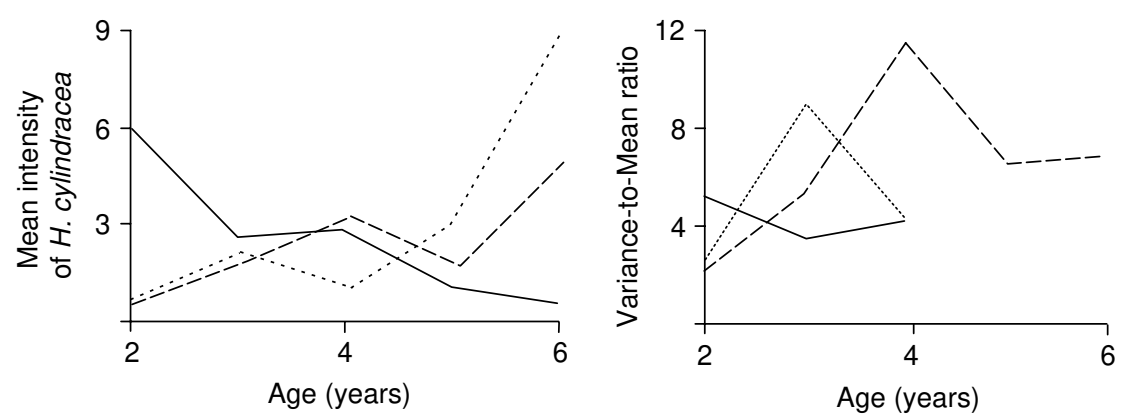

Fig. 4. Mean parasite intensity (left) and variance-to-mean ratio (right) of H. cylindracea in hybrid frogs of the three populations. Plain line: POND B population; dashed line: POND A population; dotted line: POND C population.

mortality was much higher in this population. Moreover, VMR showed a peak at POND A in 4-year-old frogs, and at POND $\mathrm{C}$ in 3 -year-old frogs, which suggests parasite-induced mortality. At POND B, the curve is flat, but the peak may have occurred at an earlier age outside the range of sizes sampled.

While the factors related to infection varied from one population to another, the genotype ( $L L$ or $R L)$ was always involved. The selected GLMs were (genotype $*$ intensity of $R$. bufonis) at POND B, $[$ condition $+($ genotype $*$ age $)]$ at POND C, and [(genotype $*$ age)] at POND A. POND B population was the only one in which the 2 parasites influenced each other. However, the influence of the intensity of $R$. bufonis on that of $H$. cylindracea diverged dramatically according to genotype (Fig. 1). Whereas $L L$ frogs carried higher numbers of $H$. cylindracea than $R L$ frogs, the latter carried higher numbers of $R$. bufonis. Moreover, the intensity of both parasites was positively related in $L L$ frogs whereas it was negatively related in $R L$ frogs.

\section{DISCUSSION}

Despite significant variation among populations, our results clearly show that genotype (parental versus hybrid) strongly influences the intensity of parasites (genotype was involved in 4 out of 5 combinations of populations and parasite species). The other significant factors were body condition and age (involved in 3 combinations). The parasites were shown to influence each other in only 1 population (POND B). Nevertheless, the incidence of lung parasites in the two frog taxa studied varied greatly from one population to another. Indeed, the infection pressure by H. cylindracea was higher in POND $\mathrm{B}$ than in the other ponds. Concomitant variation of population structure and survival suggests that local ecological conditions influenced both infection frequency and fitness. However, the descriptive nature of this study prevents us from firmly identifying the causes of these differences. Both the variation in the density of intermediate hosts in the pressures of other pathogens, and the difference in predation intensity on frogs between ponds (e.g. due to variation in predator density) could explain the observed patterns.

The parasite $H$. cylindracea proved to be the most effective for discriminating the responses of each genotype since the only significant result with $R$. bufonis was a similar influence on condition in both taxa at POND A (R. bufonis was related to a depression of condition with age). Despite variation in the responses from one pond to another, the present results suggest that $L L$ frogs were more susceptible to $H$. cylindracea than $R L$ frogs. This statement is supported by several results. In POND A, the intensity of $H$. cylindracea in $L L$ frogs decreased with age, although it increased in $R L$ frogs, suggesting a lower deleterious effect in this taxon. Indeed, we suppose that the survival of heavily infested frogs was lower in $L L$ frogs than in $R L$ frogs, thus explaining the negative relationship between age and intensity. Moreover, the body condition of $R L$ frogs in this pond did not decrease, despite higher parasite intensity, whereas body condition of $L L$ frogs decreased with age, although their parasite intensity was lower. In POND C, the intensity of $H$. cylindracea was negatively related to body condition in both taxa. Yet, the relationship was stronger in $L L$ frogs than in $R L$ frogs. However, this result has to be considered with some degree of caution because of the low number of $L L$ frogs sampled in this pond. This relative scarcity of $L L$ frogs could also be the result of the impact of parasites. Finally, the positive relationship between the intensity of each of the parasites in $L L$ frogs in POND B suggests that the defence of this taxon is lowered by the presence of another parasite, although this was observed in $R L$ frogs. Other factors can also contribute to the relationship between age and intensity, such as acquired immunity or dispersal of infected frogs.

The correlative nature of the results indeed prevents us from firmly concluding that the parasites studied have a direct impact on frog condition and frog survival. Unfortunately, very few data are available in the literature on the impact of H. cylindracea 
infection on amphibians. The first host of this fluke is usually a snail of the genus Lymnaea (Goumghar et al. 2000). The cercariae metamorphose into metacercariae in the mouth of the frog where they stay for $48 \mathrm{~h}$ before metamorphosing into adults that migrate into the lungs where they feed on blood (Grabda-Kazubska and Moczo, 1981). In contrast, the deleterious impact of $R$. bufonis has been studied in toadlets (Goater, 1992; Goater and Ward, 1992). The impact on growth is positively related to the intensity of infection, and this effect is at least partially mediated by a depression of foraging propensity (anorexia effect). Unlike $H$. cylindracea, the biological cycle of $R$. bufonis can be realised with only 1 host (Baker, 1979). Rhabdias bufonis is a protandrous hermaphrodite, which undergoes heterogonic development. Embryonated eggs produced by females in the lungs are carried out by the bronchial escalator, swallowed, pass through the intestinal tract and are then voided in the faeces. These eggs hatch in the environment and the larvae produce a free-living generation of adults. This heterogonic development in the external environment is extremely rapid. Females produce a few large eggs, which develop to infective third-stage larvae in her uterus. The larvae then consume her organs and escape through her body cuticle in a process known as matricidal endotoky. These infective larvae infect a frog through skin penetration. In general, parasites with direct life-cycles, such as R. bufonis, are unlikely to manipulate the behaviour of their host to favour transmission to a downstream host. However, Baker (1979) demonstrated that paratenic hosts might be involved in the life-cycles of species of Rhabdias. The deleterious effects of infection are thus probably directly due to the alteration of lung functioning and blood consumption. Because the foraging behaviour of $H$. cylindracea is similar to that of $R$. bufonis, we suppose that the impact of this fluke is also directly due to physiological alteration resulting from damage to lungs and consumption of blood. Nevertheless, we cannot reject the hypothesis of age-dependent immune competence for explaining age-dependent parasitic infection (Cooper and Hildemann, 1965; Pickel et al. 1981; Ujvari and Madsen, 2006). It may be suspected that the two taxa of frog differ in the risk of exposure to parasites because of difference in habitat use (Hellriegel and Reyer, 2000). However, the available literature does not support such a proposal, neither in juveniles (Tietje and Reyer, 2004) nor in adults (Holenweg-Peter, 2001).

In the present study, we decided to focus on the infection of female frogs because of their crucial role in population dynamics. However, parasitic infection in both males and juveniles should also influence host population dynamics. Despite the low probability of male shortage, because of polygynous mating system (Lengagne et al. 2006), the males could act as reservoirs for parasites. However, one could probably expect an important impact of parasites on juvenile survival because of suspected agedependence of immunity efficiency. These questions should be investigated.

The variability of the responses suggests that other factors than the studied parasites influence frog condition and survival. The lung parasites may act simultaneously as determinants and indicators of a more global host-parasite-environment system. Water frogs can host a large community of parasites that inhabit their blood (Barta et al. 1989), urine bladder, digestive tract or kidneys (Tscherner, 1966; Peters, 1977). There is insufficient knowledge of the respective pathogenic power of each of them to define the assemblage that would be the more virulent and could strongly influence population dynamics. Moreover, the respective density of each pathogen can vary according to local conditions such as the density of intermediate hosts. On the other hand, variation in frog densities between ponds could also contribute to variation in infection probability and consequently in parasite densities. Nevertheless, we are confident in our result because of the great similarity of the studied ponds because traditional fishponds in the Dombes region have the same geomorphology, the same origin, the same environment and the same management.

With regard to the competing hypotheses regarding the sensitivity of the hybrids to parental parasites, the present results support the hybrid resistance hypothesis (due to an heterosis effect) than to the hybrid susceptibility hypothesis (breaking up of gene co-adaptation). Indeed, hybrid $R L$ frogs did not suffer from higher parasitic intensity than the parental species that co-occurred with them in the same habitats. Parasite intensity in these hybrids appeared to be slightly lower than in the parental frogs. However, the theoretical implications of these results have to be interpreted with some caution because hybridogenetic $R L$ frogs are not strictly equivalent to F1 hybrids. Water frog hybrid populations are composed of several lineages, arising from a more or less ancient primary hybridization between $R$. ridibunda and $R$. lessonae. The most ancient lineages probably originated during the last glacial events (Hotz et al. 1997). Although primary hybridization probably occurred repeatedly, only few hemiclone lineages are found in natural populations of $R L$ frogs (Colon, 2004). This low hemiclonal diversity may result from natural selection by both intrinsic biological factors (compatibility with the lessonae genome) and ecological ones (adaptation to habitats usually occupied by $R$. lessonae are necessary for achieving sexual parasitism). Parasite assemblages are probably an important component of these ecological selective pressures.

Because of its descriptive character, the present study does not allow us to firmly establish causative links between the variables measured. Only 
experimental infections would make it possible to rigorously test the heterosis hypothesis. However, conceiving experimental approaches requires a basic knowledge of the relationships that have to be detected in the wild. The present study thus provides several new insights into the relationship between heterozygosity and parasite infection and, more globally, into the evolution of hybrid-parasite systems. Further studies should address the question regarding the influence of sex on parasitaemia, since sex is another important source of variability in natural populations.

We are indebted to the Pierre Vérots Foundation, the Institut Rhonalpin de Recherche en Aquaculture (IRRA), and M. Verzier, owner of pond B, for allowing us to sample frogs in their estates. Sampling was authorized by the French Ministry of the Environment and the local administration of the Ain Department (Prefecture) in accordance with French legislation. We thank Professor Eric Pattee and three anonymous referees for their constructive comments on the manuscript.

\section{REFERENCES}

Agresti, A. (1990). Categorical Data Analysis. John Wiley and Sons, New York.

Anderson, R. M. and Gordon, D. M. (1982).

Processes influencing the distribution of parasite numbers within host populations, with special emphasis on parasite-induced host mortalities. Parasitology $\mathbf{8 5}$, 373-398.

Arnold, M. L. (1997). Natural Hybridisation and Evolution. Oxford Series in Ecology and Evolution. Oxford University Press, Oxford.

Augert, D. and Joly, P. (1993). Plasticity of age at maturation in neighbouring populations of the common frog, Rana temporaria. Canadian Fournal of Zoology 71, 26-33.

Baker, M. R. (1979). The free-living and parasitic development of Rhabdias spp. (Nematoda: Rhabdiasidae) in amphibians. Canadian Fournal of Zoology 57, 161-178.

Barta, J. R., Boulard, Y. and Desser, S. S. (1989). Blood parasites of Rana esculenta from Corsica: comparison of its parasites with those of eastern North American Ranids in the context of host phylogeny. Transactions of the American Microscopical Society 108, 6-20.

Beerli, P. (1994). Genetic isolation and calibration of an average protein clock in western Paleartic water frogs of the Aegean region. Ph. D. Dissertation, University of Zürich, Switzerland.

Berger, L. and Uzzell, T. (1980). The eggs of European water frogs (Rana esculenta complex) and their hybrids. Folia Biologica (Krakow) 28, 3-25.

Bush, A. O., Lafferty, K. D., Lotz, J. M. and Shostak, A. W. (1997). Parasitology meets ecology on its own terms: Margolis et al. revisited. Fournal of Parasitology 83, 575-583.

Castanet, J., Meunier, F. and de Ricqlès, A. (1977). L'enregistrement de la croissance osseuse chez les vertébrés poïkilothermes: données comparatives et essais de synthèse. Bulletin de Biologie Franco-Belge 111, 183-202.
Colon, L. (2004). Dispersion de Rana ridibunda dans la vallée du Rhône et relations génétiques avec le complexe d'hybridation esculenta. Ph. D. thesis, Lyon 1 University, France.

Cooper, E. L. and Hildemann, W. H. (1965). The immune response of larval bullfrogs (Rana catesbeiana) to diverse antigens. Annals of the New York Academy of Sciences 126, 647-661.

Dupont, F. and Crivelli, A. J. (1988). Do parasites confer a disadvantage to hybrids? Oecologia 75, 587-592.

Fritz, R. S., Moulia, C. and Newcombe, G. (1999). Resistance of hybrid plants and animals to herbivores, pathogens, and parasites. Annual Review of Ecology and Systematics 30, 565-591.

Goater, C. P. (1992). Experimental population dynamics of Rhabdias bufonis (Nematoda) in toads (Bufo bufo): density dependence in the primary infection. Parasitology 104, 179-187.

Goater, C. P. and Ward, P. I. (1992). Negative effects of Rhabdias bufonis (Nematoda) on the growth and survival of toads (Bufo bufo). Oecologia 89, 161-165.

Goumghar, M. D., Abrous, M., Ferdonnet, D., Dreyfuss, G. and Rondelaud, D. (2000). Prevalence of Haplometra cylindracea infection in three species of Lymnaea snails in central France. Parasitology Research 86, 337-339.

Grabda-Kazubska, B. and Moczo, T. (1981). Nervous system and chaetotaxy in the cercaria of Haplometra cylindracea (Zeder 1800) (Digenea, Plagiorchiidae). Parasitology Research 65, 53-61.

Guisan, A. and Harrell, F. E. (2000). Ordinal response regression models in ecology. Fournal of Vegetation Sciences 11, 617-626.

Hellriegel, B. and Reyer, H. U. (2000). Factors influencing the composition of mixed populations of a hemiclonal hybrid and its sexual host. Fournal of Evolutionary Biology 13, 906-918.

Holenweg Peter, A.-K. (2001). Dispersal rates and distances in adult water frogs, Rana lessonae, R. ridibunda and their hybridogenetic associate, R. esculenta. Herpetologica 57, 449-460.

Hotz, H., Uzzell, T. and Berger, L. (1997). Linkage groups of protein-coding genes in western palearctic water frogs reveal extensive evolutionary conservation. Genetics 147, 255-270.

Hotz, H., Semlitsch, R. D., Gutmann, E., Guex, G.-D. and Beerli, P. (1999). Spontaneous heterosis in larval life-history traits of hemiclonal frog hybrids. Proceedings of the National Academy of Sciences, USA 96, 2171-2176.

Hudson, P. J., Dobson, A. P., Cattadori, I. M., Newborn, D., Haydon, D. T., Shaw, D. J., Benton, T. G. and Grenfell, B. T. (2002). Trophic interactions and population growth rates: describing patterns and identifying mechanisms. Philosophical Transactions of the Royal Society of London, B 35, 1259-1271.

Jakob, E. M., Marshall, S. D. and Uetz, G. W. (1996). Estimating fitness: a comparison of body condition indices. Oikos 77, 61-67.

Joly, P. (2001). The future of the selfish hemiclone: a neodarwinian approach of water frog evolution. Mitteilungen aus dem Museum für Naturkunde in Berlin 77, 31-38. 
Kuzmin, Y., Tkach, V. V. and Brooks, D. R. (2007). Two new species of Rhabdias (Nematoda, Rhabdiasidae) from the marine toad, Bufo marinus (L.) (Lissamphibia: Anura: Bufonidae), in Central America. Fournal of Parasitology 93, 159-165.

Lawless, J. F. (1987). Negative binomial and mixed Poisson regression. Canadian Fournal of Statistics $\mathbf{1 5}$, 209-225.

Lengagne, T., Grolet, O. and Joly, P. (2006). Male mating speed promotes hybridization in the Rana lessonae-Rana esculenta waterfrog system. Behavioural Ecology and Sociobiology 60, 123-130.

MacCullagh, P. and Nelder, J. A. (1989). Generalized Linear Models. Chapman and Hall, London.

Moulia, C. (1999). Parasitism of plant and animal hybrids: are facts and fates the same? Ecology 80, 392-406.

Moulia, C., Le Brun, N., Loubès, C., Marin, R. and Renaud, F. (1995). Hybrid vigour against parasites in interspecific crosses between two mice species. Heredity 74, 48-52.

Negovetic, S., Anholt, B. R., Semlitsch, R. D. and Reyer, H. U. (2001). Specific responses of sexual and hybridogenetic European waterfrog tadpoles to temperature. Ecology 82, 766-774.

Pagano, A., Joly, P. and Hotz, H. (1997). Taxon composition and genetic variation of water frogs in the mid-Rhône floodplain. Comptes-Rendus de l'Académie des Sciences de Paris, 320, 759-766.

Pagano, A. and Schmeller, D. (1999). Is recombination less negligible than previously described in hybridogenetic water frogs? In Current Studies in Herpetology (ed. Miaud, C. and Guyetant, R.), pp. 351-356. Proceedings of the 9th Ordinary General Meeting of the Societas Europaea Herpetologica, Chambéry, France.

Pagano, A., Joly, P., Plénet, S., Lehman, A. and Grolet, O. (2001). Breeding habitat partitioning in the Rana esculenta complex: the intermediate niche hypothesis supported. Ecoscience 8, 294-300.

Peters, A. (1977). Quantitative und Qualitative Aspekte des Helminthenfauna heimischer Grünfrosch-und Unkenpopulationen. Dissertation, HumboldtUniversität, Berlin, Germany.

Pickel, K., Müller, M. A. and ter Meulen, V. (1981). Analysis of age-dependent resistance to murine coronavirus JHM infection in mice. Infection and Immunity 34, 648-654.

Plénet, S., Hervant, F. and Joly, P. (2000a). Ecology of the hybridogenetic Rana esculenta complex: differential oxygen requirements of tadpoles. Evolutionary Ecology 14, 13-23.

Plénet, S., Pagano, A., Joly, P. and Fouillet, P. (2000 b). Variation of plastic responses to oxygen availability within the hybridogenetic Rana esculenta complex. Fournal of Evolutionary Biology 13, 20-29.
Plénet, S., Joly, P., Hervant, F., Fromont, E. and Grolet, O. (2005). Are hybridogenetic zones structured by environmental gradients? In situ experiments in the waterfrog hybridisation complex. Fournal of Evolutionary Biology 18, 1575-1586.

Sage, R. D., Heyneman, D., Lim, K. C. and Wilson, A. C. (1986). Wormy mice in a hybrid zone. Nature, London 324, 60-63.

Saglam, N. and Arikan, H. (2006). Endohelminth fauna of the marsh frog Rana ridibunda from Lake Hozar, Turkey. Diseases of Aquatic Organisms 72, 253-260.

Schultz, R. J. (1969). Hybridization, unisexuality, and polyploidy in the teleost Poeciliopis (Poeciliidae) and other vertebrates. The American Naturalist 103, 605-619.

Semlitsch, R. D. (1993). Effects of different predators on the survival and development of tadpoles from the hybridogenetic Rana esculenta complex. Oikos 67, 40-46.

Tietje, G. A. and Reyer, H. U. (2004). Larval development and recruitment of juveniles in a natural population of Rana lessonae and R. esculenta. Copeia, 638-646.

Tkach, V., Kuzmin, Y. and Pulis, E. E. (2006). A new species of Rhabdias from the lungs of the wood frog, Rana sylvatica, in North America: the last sibling of Rhabdias ranae? Fournal of Parasitology 92, 631-636.

Tscherner, W. (1966). Helminthofaunistische Untersuchungen an Rana esculenta $\mathrm{L}$ und $R$. ridibunda Pall., mit besonderer Berücksichtigung der Europäischen Prosotocus-Arten (Trematoda: Lecithodendriidae). Mitteilungen aus dem Museum für Naturkunde in Berlin 42, 259-279.

Tunner, H. G. (1974). Die klonale Struktur einer Wasserfroschpopulation. Zeitschrift für zoologische Systematik und Evolutionsforschung 12, 309-314.

Tunner, H. G. and Nopp, H. (1979). Heterosis in the common European waterfrog. Naturwissenschaften 66, 268-269.

Ujvari, B. and Madsen, T. (2006). Age, parasites, and condition affect humoral immune response in tropical pythons. Behavioral Ecology 17, 20-24.

Venables, W. N. and Ripley, B. D. (2002). Modern Statistics with $S$. Springer Verlag, Luxemburg.

Walton, A. C. (1949). Parasites of the Ranidae (Amphibia). Transactions of the American Microscopical Society 68, 49-54.

Whitman, G. T. (1989). Plant hybrid zones as sinks for pests. Science 244, 1490-1493.

Wilson, K., Grenfell, B. T. and Shaw, D. J. (1996). Analysis of aggregated parasite distributions: a comparison of methods. Functional Ecology 10 , 592-601. 